\title{
Effect of Various Soil Media on Disease Severity of Fusarium Wilt in Watermelon
}

\author{
Geoffrey Meru ${ }^{1}$, Cecilia McGregor ${ }^{2}$ \\ ${ }^{1}$ Horticultural Sciences Department and Tropical Research \& Education Center, University of Florida, Homestead, FL, USA \\ ${ }^{2}$ Institute of Plant Breeding, Genetics \& Genomics and Department of Horticulture, University of Georgia, Athens, GA, USA \\ Email: *gmeru@ufl.edu
}

How to cite this paper: Meru, G. and McGregor, C. (2020) Effect of Various Soil Media on Disease Severity of Fusarium Wilt in Watermelon. American Journal of Plant Sciences, 11, 1890-1898.

https://doi.org/10.4236/ajps.2020.1112135

Received: October 22, 2020

Accepted: December 6, 2020

Published: December 9, 2020

Copyright (c) 2020 by author(s) and Scientific Research Publishing Inc. This work is licensed under the Creative Commons Attribution International License (CC BY 4.0).

http://creativecommons.org/licenses/by/4.0/

\begin{abstract}
Fusarium wilt is a major disease of watermelon (Citrullus lanatus) caused by Fusarium oxysporum f. sp. niveum (Fon). Use of host resistance is the most effective management strategy for the disease, and a major objective for breeding programs. Screening assays rely on the ability to discriminate resistant and susceptible genotypes in segregating populations. However, complex interactions between Fon and the soil environment can influence symptom development and disease severity rating. In the current study, severity of Fusarium wilt (race 1$)$ in sand-peat $(1: 1 \mathrm{v} / \mathrm{v})$, sand-perlite $(1: 1)$, sand-peat-vermiculite (4:1:1), peat-perlite (1:1) and Fafard 3B potting media was compared among five watermelon cultivars: Calhoun Gray (resistant), SunSugar (resistant), Allsweet (moderately resistant), Sugar Baby (susceptible) and Charleston Gray (susceptible). Plant biomass (average dry weight/plant) was lowest in peat-perlite $(1.67 \mathrm{~g})$ and sand-peat $(2.16 \mathrm{~g})$, and was significantly different ( $\alpha=0.05$ ) from that of sand-perlite ( $3.48 \mathrm{~g})$, sand-peat-vermiculite $(4.94 \mathrm{~g})$ and Fafard 3B (6.90 g). Conversely, disease severity [area under disease progress curve (AUDPC)] across cultivars was significantly higher in peat-perlite $($ AUDPC $=62.96)$ and sand-peat $($ AUDPC $=40.87)$, than in sand-perlite $(A U D P C=11.55)$, sand-peat-vermiculite $($ AUDPC $=10.67)$ and Fafard 3B (AUDPC $=9.29)$. Consistent discrimination $(\alpha=0.05)$ of resistant and susceptible cultivars was realized in sand-peat-vermiculite and Fafard 3B, but was not possible in peat-perlite, sand-peat and sand-perlite. Collectively, these findings support suitability of sand-peat-vermiculite and Fafard 3B for routine screening of Fusarium wilt resistance in watermelon.
\end{abstract}

\section{Keywords}

Breeding, Citrullus lanatus, Pathogen, Fusarium oxysporum, Race 1, Soil-Type, AUDPC 


\section{Introduction}

Watermelon (Citrullus lanatus) is an economically important crop of the $\mathrm{Cu}$ curbitaceae family popular for its sweet edible flesh [1]. Watermelon production is severely limited by a vascular disease caused by Fusarium oxysporum f. sp. niveum (Fon) (E. F. Sm.) W. C. Snyder \& H. N. Han. [2] [3] [4] [5]. There are four races of Fon designated 0, 1,2 and 3 based on their aggressiveness or the ability to overcome specific resistance in a set of differential cultivars [3] [5] [6] [7].

Management of Fusarium wilt is difficult because of the long-term survival of the pathogen's chlamydospores in the soil and the evolution of new races [3] [6] [8]. Examples of management options for the disease include use of disease-free planting materials, crop rotation, chemical and biological fumigation [3] [6] [9], resistant root-stocks [10], suppressive soils [11] [12] [13] and induced resistance [12] [14]. The ecological risk of the chemical fumigants has led to the phasing out of methyl-bromide (Montreal Protocol and the Clean Air Act, 1998) leaving even fewer options for managing Fusarium wilt. Watermelon growers prefer resistant cultivars as the primary management method for Fusarium wilt [4] [6] [8] [9] [15] [16] [17].

Breeding for resistant cultivars depends on the ability to discriminate resistant and susceptible genotypes, which can be difficult due to complex interactions between Fon, the host and the environment [2] [18]. Important host factors contributing to the development of Fusarium wilt include the age and inherent susceptibility of the plant to Fon [2] [3] [6] [19] [20] [21], while pathogen factors include the virulence of the race and inoculum density. Martyn and McLaughlin [4] reported that high inoculum density elicited higher disease severity than lower inoculum density in watermelon. Other important environmental factors include temperature, light, moisture levels and soil type [18] [19].

The mechanisms and interactions between soil-borne Fusarium species and the soil environment are poorly understood [2] making the choice of soil medium an important factor in disease screening assays. Depending on the plant species, certain soil media can suppress, while others increase severity of soil-borne diseases. For example, compost and other soils have been shown to suppress the development of soil-borne diseases even in presence of pathogens [19] [22]. Cohen et al. [19] reported that peat-based soil media induced susceptibility of melons to Fusarium oxysporum f. sp. melonis. On the contrary, peat-based media has been shown to suppress disease development for some soil-borne pathogens such as Alternaria brassicicola, Leptosphaeria maculans, Rhizoctonia solani and Fusarium oxysporum f. sp. lycopersici [23]. It is therefore imperative to determine a reliable pathogen-media combination for screening assays involving soil-borne diseases. In cucurbit breeding programs, soil media used in disease screening with Fusarium species include sand-peat-vermiculite [16], vermiculite-peat moss [17], commercial potting mix such as Metromix [2], Metromix-sand-vermiculite [24], sand-soil [25], peat-perlite, sand-peat and sand-perlite [19].

Currently, no information is available on the effect of different soil media on 
Fusarium wilt severity in watermelon. Therefore, the objective of the current study was to evaluate the effect of five different soil media on disease severity of Fon race 1 in watermelon.

\section{Materials and Methods}

\subsection{Plant Materials and Soil Media}

Five watermelon cultivars with known disease reactions to Fon race 1 [Sugar Baby (susceptible; Reimer Seed Company, Mount Holly, NC, USA), Charleston Gray (susceptible, Reimer Seed Company), Allsweet (moderately resistant; SeedWay, NY, USA), SunSugar (resistant; USDA Germplasm collection), and Calhoun Gray (resistant; Twilley Seeds, SC, USA)] [6] [16] [17] [24] [26] [27] [28] [28] were used in this study. Four of the soil media used in the study were obtained locally and mixed in specific ratios [sand-peat (1:1 v/v), sand-perlite (1:1), sand-peat-vermiculite (4:1:1), and peat-perlite (1:1)]. In addition, a commercial soil mix, Fafard 3B (Sun Gro Horticulture, MA, USA), was included.

\subsection{Inoculum Preparation}

Fon race 1 [(B05-07), provided by Anthony Keinath, Clemson University], was grown (14 h/10h dark cycle) on quarter-strength potato dextrose agar (Becton, Dickinson and Company, NJ, USA) for 12 days and $1 \mathrm{~cm}^{2}$ agar plugs were transferred into $250 \mathrm{~mL}$ Erlenmeyer flasks containing $100 \mathrm{~mL}$ potato dextrose broth (Becton, Dickinson and Company). The fungal cultures were grown (14 $\mathrm{h} / 10 \mathrm{~h}$ dark cycle) on a Mini-Orbital shaker (Henry Troemner, NJ, USA) at 200 rpm for 10 days and the inoculum was filtered through four layers of sterile cheese cloth. The microconidial concentration in the inoculum suspension was determined using a hemacytometer (Hausser Scientific, PA, USA) and adjusted to $1 \times 10^{6} \mathrm{~mL}^{-1}$ using sterile water.

\subsection{Greenhouse Evaluations}

Seeds were sown in $20.32 \mathrm{~cm}$ pots (Sun Gro Horticulture, MA, USA) filled with steam-pasteurized media amended with $14 \mathrm{~N}-4.2 \mathrm{P}-11.6 \mathrm{~K}$ controlled release fertilizer (Osmocote; Scotts, Marysville, $\mathrm{OH}$ ). Plants were inoculated at cotyledonary stage by pouring $40 \mathrm{~mL}$ of inoculum around each seedling using a beaker. For each soil medium, four seeds of each cultivar were sown per replication with a total of three replications in a randomized complete block design. Mock inoculations were carried out as described above but using sterile potato dextrose broth diluted (1:10) with sterile water. The pots were transferred into hole-less trays $(53.3 \times 27.9 \times 5.1 \mathrm{cM}$, Sun Gro Horticulture, MA, USA) to contain run-off. The experiment was carried out in Mar. 2014 and repeated in June of the same year. The temperature in the greenhouse was maintained at $27^{\circ} \mathrm{C} \pm 3^{\circ} \mathrm{C}$.

\subsection{Data Collection and Analysis}

Plants were evaluated for symptom severity on a scale of 0 to 5 , with a score of 0 
representing asymptomatic plants, a score of 1 for plants showing initial wilting on one leaf, a score of 2 for plants showing continued wilting in more than one leaf, a score of 3 for plants with all the leaves wilted, a score of 4 for plants with all leaves wilted and stem collapsing, and a score of 5 for dead plants [30]. Disease severity data were collected at 4, 7, 10,13,16, 19 and 27 days after inoculation (DAI) and the area under disease progress curve (AUDPC) determined by the trapezoidal integration method [31]. To determine the vigor of plants growing in the soil media, average dry weight of the mock-inoculated controls at 27 DAI was determined by oven-drying plants at $55^{\circ} \mathrm{C} \pm 5^{\circ} \mathrm{C}$ for four days. The data, AUDPC and dry weight were analyzed using PROC GLM procedure of SAS [32] and mean separation determined using the Tukey's significance difference test [33].

\section{Results}

No significant differences $(\alpha=0.05)$ in disease severity were observed between the two experiments (data not shown), therefore joint analysis was conducted for the data.

\subsection{Plant Vigor}

Plant vigor, as indicated by plant biomass (average dry weight/plant), varied across media and ranged from $1.67 \mathrm{~g}$ to $6.90 \mathrm{~g}$ (Table 1, Figure 1). Plant vigor was lowest in peat-perlite $(1.67 \mathrm{~g})$ followed by sand-peat $(2.16 \mathrm{~g})$. The plant biomass in the two media was significantly lower $(\alpha=0.05)$ than that in sand-perlite $(3.48 \mathrm{~g})$, sand-peat-vermiculite $(4.94 \mathrm{~g})$ and Fafard 3B (6.90 g) (Table 1, Figure 1).

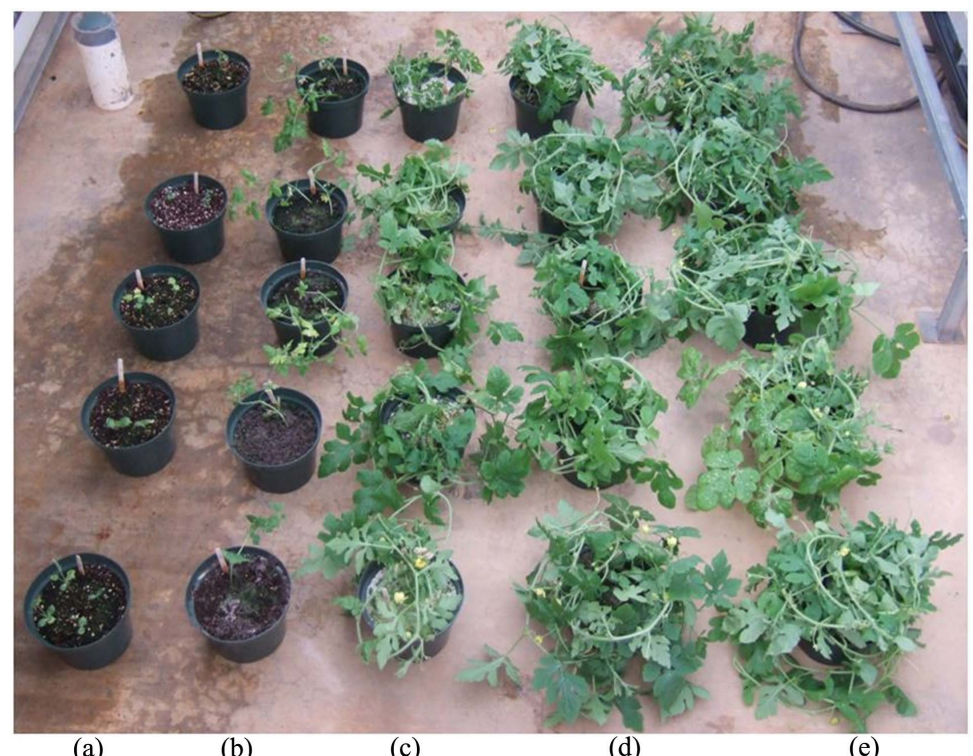

(a)

(b)

(c)

(d)

(e)

Figure 1. Mock inoculated watermelon plants at 27 days after inoculation grown in (a) peat-perlite (1:1); (b) sand-peat (1:1); (c) sand-perlite (1:1); (d) sand-peat-vermiculite (4:1:1); and (e) Fafard 3B media. 
Table 1. Plant biomass (dry weight/plant) of mock inoculated watermelon plants at 27 days after inoculation in peat-perlite (1:1), sand-peat (1:1), sand-perlite (1:1), Fafard 3B, and sand-peat-vermiculite (4:1:1).

\begin{tabular}{cc}
\hline Soil medium & Dry weight $(\mathrm{g})^{\mathrm{z}}$ \\
\hline Peat-perlite & $1.67^{\mathrm{d}}$ \\
Sand-peat & $2.16^{\mathrm{c}}$ \\
Sand-perlite & $3.48^{\mathrm{ab}}$ \\
Sand-peat-vermiculite & $4.94^{\mathrm{ab}}$ \\
Fafard 3B & $6.90^{\mathrm{a}}$ \\
\hline
\end{tabular}

${ }^{2}$ Means separated by the same letter are not significantly different.

\subsection{Disease Severity}

Disease severity [area under disease progress curve (AUDPC)] was highest in peat-perlite, followed by sand-peat (Table 2). Overall, there was no significantly difference in disease severity in sand-perlite, Fafard 3B and sand-peat-vermiculite (Table 2). As expected, Sugar Baby and Charleston Gray were the most susceptible across all media, while Allsweet, SunSugar and Calhoun Gray were the most resistant (Table 3). In peat-perlite, disease severity was high across all cultivars, and there was no consistent significant difference between susceptible cultivars and resistant cultivars (Figure 2(a)). However, Calhoun Gray showed significantly greater resistance than all the cultivars in this medium. In sand-peat, the moderately resistant cultivar, Allsweet, showed no significant difference in susceptibility when compared to Sugar Baby and Charleston Gray (Figure 2(b)). However, Calhoun Gray and SunSugar were significantly more resistant than the two susceptible cultivars in this medium. In sand-perlite, all the cultivars exhibited minimal symptoms, and there was no significant difference in disease severity (Figure 2(c)). However, in sand-peat-vermiculite and Fafard 3B, there was a clear delineation in disease severity between the susceptible (Sugar Baby and Charleston Gray) and the resistant cultivars (Allsweet, Calhoun Gray and SunSugar) (Figure 2(d) and Figure 2(e)).

\section{Discussion}

Complex interactions between Fon and the soil environment make selection of a reliable soil medium an important factor in Fusarium wilt screening assays [2] [18]. In the current study, severity of Fusarium wilt in five soil media was compared to identify the best media for routine screening assays. Poor plant vigor and high disease severity were observed in peat-perlite and sand-peat media. This was expected because poor plant vigor generally reduces the ability of plants to resist diseases [3] [19] [20] [21]. In the two media, the resistant cultivars (Calhoun Gray, SunSugar and Allsweet) were also highly susceptible. In melon, Cohen et al. [19] reported that seedlings grown in peat-based media developed more severe disease symptoms than those grown in media lacking peat. However, the growth vigor of the seedlings in these media was not reported, thus 


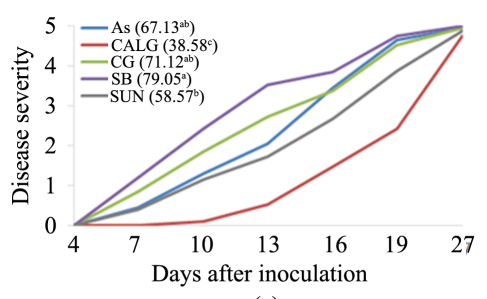

(a)



(c)

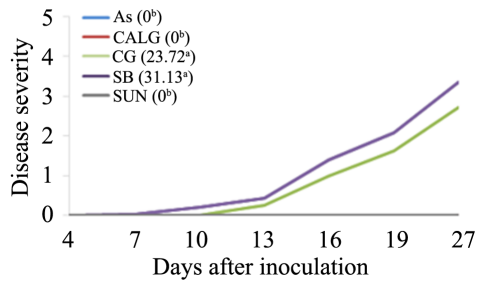

(e)

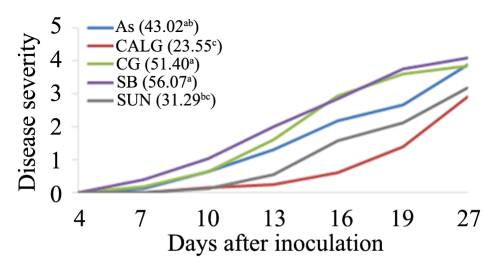

(b)

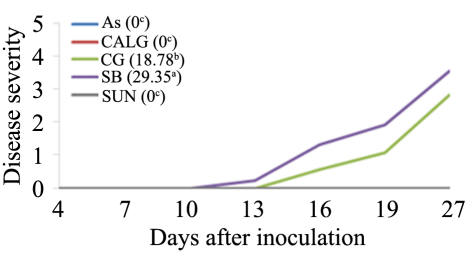

(d)

Figure 2. Disease severity in Allsweet (AS), Calhoun Gray (CALG), Charleston Gray (CG), Sugar Baby (SB) and Sun Sugar (SUN) inoculated with race 1 of Fusarium oxysporum f. sp. niveumin (a) peat-perlite (1:1); (b) sand-peat (1:1); (c) sand-perlite (1:1); (d) sand-peat-vermiculite (4:1:1); and (e) Fafard 3B. Area under disease progress curve values are given in parentheses. Means separated by the same letter are not significantly different.

Table 2. Disease severity [area under disease progress curve (AUDPC)] across cultivars in peat-perlite (1:1), sand-peat (1:1), sand-perlite (1:1), Fafard 3B, and sand-peat-vermiculite $(4: 1: 1)$.

\begin{tabular}{cc}
\hline Soil medium & Mean AUDPC \\
\hline Peat-perlite & $62.96^{\mathrm{a}}$ \\
Sand-peat & $40.87^{\mathrm{b}}$ \\
Sand-perlite & $11.55^{\mathrm{c}}$ \\
Sand-peat-vermiculite & $9.29^{\mathrm{c}}$ \\
Fafard 3B & $10.67^{\mathrm{c}}$ \\
\hline
\end{tabular}

${ }^{\mathrm{z}}$ Means separated by the same letter are not significantly different.

Table 3. Disease severity [area under disease progress curve (AUDPC)] of cultivars across all media.

\begin{tabular}{cc}
\hline Cultivars & Mean AUDPC \\
\hline Sugar Baby & $41.41^{\mathrm{a}}$ \\
Charleston Gray & $36.83^{\mathrm{a}}$ \\
Allsweet & $23.26^{\mathrm{b}}$ \\
SunSugar & $18.96^{\mathrm{bc}}$ \\
Calhoun Gray & $13.80^{\mathrm{c}}$ \\
\hline
\end{tabular}

${ }^{z}$ Means separated by the same letter are not significantly different. 
difficult to compare. Generally, good plant vigor was observed in sand-perlite; however, disease development in this media was suppressed, even for the susceptible cultivars (Sugar Baby and Charleston Gray). Consequently, it was not possible to discriminate resistant and susceptible cultivars in this medium. Similar observations were reported in melon, whereby resistant and susceptible cultivars inoculated with Fusarium could not be discriminated in a sand-perlite medium [19]. In sand-peat-vermiculite and Fafard 3B, high disease severity was observed in susceptible cultivars, while the resistant cultivars remained asymptomatic. Collectively, this study established that among the media studied, sand-peat-vermiculite and Fafard 3B were ideal for discriminating resistant and susceptible cultivars in Fusarium race 1 screening assays. Although sand-peat-vermiculite is routinely used in Fusarium screening assays [16] [30] [34], Fafard 3B is a suitable commercial-mix alternative [34].

\section{Conflicts of Interest}

The authors declare no conflicts of interest.

\section{References}

[1] Robinson, R.W. and Decker-Walters, D. (1997) Cucurbits. CAB International Publishing, Wallingford.

[2] Boyhan, G., Langston, D., Granberry, D., Lewis, P. and Linton, D. (2003) Resistance to Fusarium Wilt and Root-Knot Nematode in Watermelon Germplasm. Cucurbit Genetics Cooperative Report, 26, 18-25.

[3] Egel, D.S. and Martyn R.D. (2007) Fusarium Wilt of Watermelon and Other Cucurbits. Plant Health Instructor. https://www.apsnet.org/edcenter/disandpath/fungalasco/pdlessons/Pages/Fusarium Watermelon.aspx

[4] Martyn, R. and McLaughlin R. (1983) Effects of Inoculum Concentration on the Apparent Resistance of Watermelons to Fusarium oxysporum f. sp. niveum. Plant Disease, 67, 493-495. https://doi.org/10.1094/PD-67-493

[5] Zhou, X., Everts, K. and Bruton B. (2010) Race 3, a New and Highly Virulent Race of Fusarium oxysporum f. sp. niveum Causing Fusarium Wilt in Watermelon. Plant Disease, 94, 92-98. https://doi.org/10.1094/PDIS-94-1-0092

[6] Bruton, B. (1998) Soilborne Diseases in Cucurbitaceae: Pathogen Virulence and Host Resistance. Cucurbitaceae, 98, 143-166.

[7] Wehner, T. (2008) Watermelon. In: Prohens, J. and Nuez, F., Eds., Vegetables I: Asteraceae, Brassicaceae, Chenopodicaceae, and Cucurbitaceae, Springer, New York, 381-418. https://doi.org/10.1007/978-0-387-30443-4_12

[8] Lin, Y., Chen, K., Liou, T., Huang, J. and Chang, P.F. (2009) Development of a Molecular Method for Rapid Differentiation of Watermelon Lines Resistant to Fusarium oxysporum f. sp. niveum. Botanical Studies, 50, 273-280.

[9] Hopkins, D., Lobinske, R. and Larkin, R. (1992) Selection for Fusarium oxysporum f. sp. niveum Race 2 in Monocultures of Watermelon Cultivars Resistant to Fusarium Wilt. Phytopathology, 82, 290-293. https://doi.org/10.1094/Phyto-82-290

[10] Kuniyasu, K. (1980) Seed Transmission of Fusarium Wilt of Bottle Gourd, Lagenaria siceraria, Used as Rootstock of Watermelon. Japan Agricultural Research Quar- 
terly, 14, 157-162.

[11] Njoroge, S., Riley, M. and Keinath, A. (2008) Effect of Incorporation of Brassica spp. Residues on Population Densities of Soilborne Microorganisms and on Damping-Off and Fusarium Wilt of Watermelon. Plant Disease, 92, 287-294. https://doi.org/10.1094/PDIS-92-2-0287

[12] Biles, C. and Martyn, R. (1989) Local and Systemic Resistance Induced in Watermelons by Formae Speciales of Fusarium oxysporum. Phytopathology, 79, 856-860. https://doi.org/10.1094/Phyto-79-856

[13] Sun, S. and Huang, J. (1985) Formulated Soil Amendment for Controlling Fusarium Wilt and Other Soilborne Diseases. Plant Disease, 69, 917-920. https://doi.org/10.1094/PD-69-917

[14] Cohen, R. (2002) $\beta$-Aminobutyric Acid-Induced Resistance against Plant Pathogens. Plant Disease, 86, 448-457. https://doi.org/10.1094/PDIS.2002.86.5.448

[15] Lin, Y.H., Chen, K.S., Chang, J.Y., Wan, Y.L., Hsu, C.C., Huang, J.W. and Chang, P.F.L. (2010) Development of the Molecular Methods for Rapid Detection and Differentiation of Fusarium oxysporum and F. oxysporum f. sp. niveum in Taiwan. New Biotechnology, 27, 409-418. https://doi.org/10.1016/j.nbt.2010.05.005

[16] Martyn, R. and Netzer, D. (1991) Resistance to Races 0, 1, and 2 of Fusarium Wilt of Watermelon in Citrullus sp. PI-296341-FR. HortScience, 26, 429-432. https://doi.org/10.21273/HORTSCI.26.4.429

[17] Zhou, X.G. and Everts, K.L. (2004) Quantification of Root and Stem Colonization of Watermelon by Fusarium oxysporum f. sp. niveum and Its Use in Evaluating Resistance. Phytopathology, 94, 832-841.

https://doi.org/10.1094/PHYTO.2004.94.8.832

[18] Scholthof, K.B.G. (2007) The Disease Triangle: Pathogens, the Environment and Society. Nature Reviews Microbiology, 5, 152-156. https://doi.org/10.1038/nrmicro1596

[19] Cohen, R., Burger, Y., Horev, C., Saar, U. and Raviv, M. (2008) Peat in the Inoculation Medium Induces Fusarium Susceptibility in Melons. Plant Breeding, 127, 424-428. https://doi.org/10.1111/j.1439-0523.2008.01496.x

[20] Geiger, H. and Heun, M. (1989) Genetics of Quantitative Resistance to Fungal Diseases. Annual Review of Phytopathology, 27, 317-341. https://doi.org/10.1146/annurev.py.27.090189.001533

[21] Zhou, X.G. and Everts, K.L. (2007) Characterization of a Regional Population of Fusarium oxysporum f. sp. niveum by Race, Cross Pathogenicity, and Vegetative Compatibility. Phytopathology, 97, 461-469.

https://doi.org/10.1094/PHYTO-97-4-0461

[22] Larkin, R., Hopkins, D. and Martin, F. (1996) Suppression of Fusarium Wilt of Watermelon by Nonpathogenic Fusarium oxysporum and Other Microorganisms Recovered from a Disease-Suppressive Soil. Phytopathology, 86, 812-819. https://doi.org/10.1094/Phyto-86-812

[23] Tahvonen, R. (1982) The Suppressiveness of Finnish Light Colored Sphagnum Peat. Agricultural and Food Science, 54, 345-356. https://doi.org/10.23986/afsci.72115

[24] Wechter, P., Kousik, C., McMillan, M. and Levi, A. (2012) Identification of Resistance to Fusarium oxysporum f. sp. niveum Race 2 in Citrullus lanatus var. citroides Plant Introductions. HortScience, 47, 334-338. https://doi.org/10.21273/HORTSCI.47.3.334

[25] Lambel, S., Lanini, B., Vivoda, E., Fauve, J., Wechter, W.P., Harris-Shultz, K.R., 
Massey, L. and Levi, A. (2014) A Major QTL Associated with Fusarium oxysporum Race 1 Resistance Identified in Genetic Populations Derived from Closely Related Watermelon Lines Using Selective Genotyping and Genotyping-by-Sequencing for SNP Discovery. Theoretical and Applied Genetics, 127, 2105-2115. https://doi.org/10.1007/s00122-014-2363-2

[26] Elmstrom, G. and Hopkins, D. (1981) Resistance of Watermelon Cultivars to Fusarium Wilt. Plant Disease, 65, 825-827. https://doi.org/10.1094/PD-65-825

[27] Gunter, C. and Egel, S.D. (2012) Staminate Flower Production and Fusarium Wiltreaction of Diploid Cultivars Used as Pollenizers for Triploid Watermelon. HortTechnology Hortte, 22, 694-699.

https://doi.org/10.21273/HORTTECH.22.5.694

[28] Netzer, D. and Weintall, C. (1980) Inheritance of Resistance in Watermelon to Race 1 of Fusarium oxysporum f. sp. niveum. Plant Disease, 64, 853-854. https://doi.org/10.1094/PD-64-853

[29] Zhou, X.G. and Everts K.L. (2003) Races and Inoculum Density of Fusarium oxysporum f. sp. niveum in Commercial Watermelon Fields in Maryland and Delaware. Plant Disease, 87, 692-698. https://doi.org/10.1094/PDIS.2003.87.6.692

[30] Meru, G. and McGregor, C. (2016) Genotyping by Sequencing for SNP Discovery and Genetic Mapping of Resistance to Race 1 of Fusarium oxysporum in Watermelon. Scientia Horticulturae, 209, 31-40. https://doi.org/10.1016/j.scienta.2016.06.005

[31] Shaner, G. and Finney, R. (1977) The Effect of Nitrogen Fertilization on the Expression of Slow-Mildewing Resistance in Knox Wheat. Phytopathology, 67, 1051-1056. https://doi.org/10.1094/Phyto-67-1051

[32] SAS Institute Inc. (1999) SAS/STAT User's Guide. Version 7-1, SAS Institute Inc., Cary.

[33] Ott, R.L. and Longnecker, M. (2001) An Introduction to Statistical Methods and Data Analysis. Duxbury Press, California.

[34] Meru, G. and McGregor, C. (2016) A Genetic Locus Associated with Resistance to Fusarium oxysporum f. sp. niveum Race 2 in Citrullus lanatus-Type Watermelon. Journal of the American Society for Horticultural Science, 141, 617-622. https://doi.org/10.21273/JASHS03890-16

[35] Fall, L.A., Clevenger, J. and McGregor, C. (2018) Assay Development and Marker Validation for Marker Assisted Selection of Fusarium oxysporum f. sp. niveum Race 1 in Watermelon. Molecular Breeding, 38, Article No. 130.

https://doi.org/10.1007/s11032-018-0890-2 